This is a pre-print version of a paper currently under revision.

Please cite this paper as: Tilga, H., Kalajas-Tilga, H., Hein, V., Raudsepp, L.\& Koka, A. (2021). One-year Follow-up Data on the Face-to-face Autonomy-Supportive Intervention Program for Physical Education Teachers. Preprint.

Letter to the Editor

\title{
One-year Follow-up Data on the Face-to-face Autonomy-Supportive Intervention Program for Physical Education Teachers
}

Henri Tilga ${ }^{1}$, Hanna Kalajas-Tilga ${ }^{1}$, Vello Hein ${ }^{1}$, Lennart Raudsepp ${ }^{1}$, and Andre Koka ${ }^{1}$

${ }^{1}$ Institute of Sport Sciences and Physiotherapy, Faculty of Medicine, University of Tartu.

This work was supported by the Estonian Research Council grant (PUT 1542) and by European Social Fund, project 2014-2020.1.02.18-0645 (Enhancement of Research and Development Capability of Teacher Education Competence Centre Pedagogicum).

Sport Sciences and Physiotherapy, Faculty of Medicine, University of Tartu, 4 Ujula St.,

\footnotetext{
Tartu, Tartu county 51008, e-mail: henri.tilga@ut.ee
} 
This is a pre-print version of a paper currently under revision.

Please cite this paper as: Tilga, H., Kalajas-Tilga, H., Hein, V., Raudsepp, L.\& Koka, A. (2021). One-year

Follow-up Data on the Face-to-face Autonomy-Supportive Intervention Program for Physical

Education Teachers. Preprint.

\section{One-year Follow-up Data on the Face-to-face Autonomy-Supportive Intervention}

\section{Program for Physical Education Teachers}

Dear Editor,

In a recent manuscript published in International Journal of Sport Psychology, entitled "Effects of a brief one-day autonomy-supportive intervention on improving basic psychological needs, motivation, and behaviours of physical activity among middle-school students: A multidimensional approach", we reported that a one-day eight-hour AutonomySupportive Intervention Program for Physical Education (ASIP-PE) was effective (Tilga et al., in press) in changing students' perceptions of their physical education (PE) teachers' cognitive and procedural autonomy support at a one-month follow-up, compared to control group students. After the intervention, a significant increase was also found in the experimental group students' need satisfaction for autonomy and competence. Also, a significant decrease was found in experimental group students' perceptions of their PE teachers' intimidation and negative conditional regard, and in students' need frustration for autonomy. This letter is to briefly convey additional data regarding the long-term benefits of ASIP-PE now that we have been able to conduct one-year follow-up analyses.

A two (study group: experimental vs. control) x three (time: baseline vs. one-month vs. one-year follow-up) randomized controlled design was used. The final sample for experimental group comprised of 15 PE teachers and their 116 secondary school students (57 boys and 59 girls) ranging from 13 to 15 years old $(M=13.86 ; S D=0.81)$. The final sample for control group comprised of 16 PE teachers and their 160 secondary school students (85 boys and 75 girls) ranging from 13 to 15 years old $(M=14.26 ; S D=0.68)$. See Tilga et al. (in press) for study details regarding approval from the university ethics committee, participants consent and the students' online questionnaire completions regarding perceptions of their PE 
This is a pre-print version of a paper currently under revision.

Please cite this paper as: Tilga, H., Kalajas-Tilga, H., Hein, V., Raudsepp, L.\& Koka, A. (2021). One-year Follow-up Data on the Face-to-face Autonomy-Supportive Intervention Program for Physical Education Teachers. Preprint.

teachers' cognitive, organizational and procedural autonomy support (Tilga et al., 2017), controlling use of grades, intimidation and negative conditional regard (Hein et al., 2015), students' psychological need frustration and satisfaction for autonomy, competence and relatedness (Haerens et al., 2015), students' identified regulation and intrinsic motivation (Goudas et al., 1994), and self-reported leisure-time physical activity (Godin \& Shepard, 1985). At one-year follow-up, all measures had acceptable internal reliability ( $\alpha$ s .74-.87). On a repeated measures ANOVA, contrasts were specified for the within-participant factor 'time', using the baseline as a reference for comparing student perceptions at the onemonth and one-year follow-up periods. Analyses revealed that experimental group students experienced significantly higher perceptions of teachers' cognitive autonomy support compared to control group students at both one-month $\left(\mathrm{F}(1,274)=14.568, p<0.0001, \eta_{\mathrm{p}}{ }^{2}=\right.$ $0.050)$ and at one-year $\left(\mathrm{F}(1,274)=10.438, p<0.001, \eta_{\mathrm{p}}{ }^{2}=0.037\right)$ follow-up. Also, analyses revealed that experimental group students demonstrated significantly higher perceptions of teachers' procedural autonomy support compared to control group students at both one-month $\left(\mathrm{F}(1,274)=11.256, p<0.001, \eta_{\mathrm{p}}^{2}=0.039\right)$ and at one-year $(\mathrm{F}(1,274)=$ 7.767, $\left.p=0.006, \eta_{\mathrm{p}}^{2}=0.028\right)$ follow-up. Results additionally indicated that experimental group students experienced significantly lower intimidation behaviour from their teacher compared to control group students at both one-month $\left(\mathrm{F}(1,274)=19.930, p<0.0001, \eta_{\mathrm{p}}{ }^{2}=\right.$ $0.068)$ and at one-year $\left(\mathrm{F}(1,274)=6.984, p=0.009, \eta_{\mathrm{p}}{ }^{2}=0.025\right)$ follow-up. Also, analyses indicated that experimental group students experienced significantly higher need satisfaction for autonomy compared to control group students at both one-month $(\mathrm{F}(1,274)=6.240, p=$ $\left.0.013, \eta_{\mathrm{p}}{ }^{2}=0.022\right)$ and at one-year $\left(\mathrm{F}(1,274)=4.070, p=0.045, \eta_{\mathrm{p}}{ }^{2}=0.015\right)$ follow-up. In conclusion, these follow-up analyses demonstrated that ASIP-PE for PE teachers had enduring effects on students' perceptions of their PE teachers' intimidation behaviour, 
This is a pre-print version of a paper currently under revision.

Please cite this paper as: Tilga, H., Kalajas-Tilga, H., Hein, V., Raudsepp, L.\& Koka, A. (2021). One-year Follow-up Data on the Face-to-face Autonomy-Supportive Intervention Program for Physical Education Teachers. Preprint.

1

cognitive and procedural autonomy support and on the students' experiences of autonomy need satisfaction. These results are similar to the previous intervention study of the Webbased Autonomy-supportive Intervention Program (Tilga et al., 2019) for PE teachers in which enduring effects on students' perceptions of autonomy need satisfaction was found at 15-month follow-up (Tilga et al., 2020). These findings indicate that PE teachers likely use their professional development experience to ensure long lasting benefits in their knowledge about autonomy-supportive behaviour. Future studies are suggested to examine the effectiveness of a combined autonomy support intervention study of a face-to-face and webbased approach.

Sincerely,

Henri Tilga, Research Fellow

Institute of Sport Sciences and Physiotherapy

Faculty of Medicine

University of Tartu

4 Ujula Street, EE 51008 Tartu, Estonia

E-mail: henri.tilga@ut.ee

Hanna Kalajas-Tilga, PhD Student

Institute of Sport Sciences and Physiotherapy

Faculty of Medicine

University of Tartu

4 Ujula Street, EE 51008 Tartu, Estonia

E-mail: hanna.kalajas-tilga@ut.ee

Vello Hein, Research Fellow

Institute of Sport Sciences and Physiotherapy

Faculty of Medicine

University of Tartu

4 Ujula Street, EE 51008 Tartu, Estonia

E-mail: vello.hein@ut.ee

Lennart Raudsepp, Professor of Sport Psychology

Institute of Sport Sciences and Physiotherapy

Faculty of Medicine

University of Tartu

4 Ujula Street, EE 51008 Tartu, Estonia

E-mail: lennart.raudsepp@ut.ee 
This is a pre-print version of a paper currently under revision.

Please cite this paper as: Tilga, H., Kalajas-Tilga, H., Hein, V., Raudsepp, L.\& Koka, A. (2021). One-year Follow-up Data on the Face-to-face Autonomy-Supportive Intervention Program for Physical Education Teachers. Preprint.

1 Andre Koka, Associate Professor in Didactics of Physical Education

2 Institute of Sport Sciences and Physiotherapy

3 Faculty of Medicine

4 University of Tartu

54 Ujula Street, EE 51008 Tartu, Estonia

6 E-mail: andre.koka@ut.ee 
This is a pre-print version of a paper currently under revision.

Please cite this paper as: Tilga, H., Kalajas-Tilga, H., Hein, V., Raudsepp, L.\& Koka, A. (2021). One-year

Follow-up Data on the Face-to-face Autonomy-Supportive Intervention Program for Physical

Education Teachers. Preprint.

\section{References}

Godin, G., \& Shephard, R. J. (1985). A simple method to assess exercise behavior in the community. Canadian Journal of Applied Sport Sciences. Journal Canadien Des Sciences Appliquees Au Sport, 10(3), 141-146.

Goudas, M., Biddle, S., \& Fox, K. (1994). Perceived locus of causality, goal orientations, and perceived competence in school physical education classes. British Journal of Educational Psychology, 64, 453-463. https://doi.org/10.1111/j.2044$\underline{\text { 8279.1994.tb01116.x }}$

Haerens, L., Aelterman, N., Vansteenkiste, M., Soenens, B., \& Van Petegem, S. (2015). Do perceived autonomy-supportive and controlling teaching relate to physical education students' motivational experiences through unique pathways? Distinguishing between the bright and dark side of motivation. Psychology of Sport and Exercise, 16, 26-36. https://doi.org/10.1016/j.psychsport.2014.08.013

Hein, V., Koka, A., \& Hagger, M. S. (2015). Relationships between perceived teachers' controlling behaviour, psychological need thwarting, anger and bullying behaviour in high-school students. Journal of Adolescence, 42, 103-114. https://doi.org/10.1016/j.adolescence.2015.04.003

Tilga, H., Hein, V., \& Koka, A. (2017). Measuring the perception of the teachers' autonomy-supportive behavior in physical education: Development and initial validation of a multi-dimensional instrument. Measurement in Physical Education and Exercise Science, 21(4), 244-255. https://doi.org/10.1080/1091367X.2017.1354296

Tilga, H., Hein, V., \& Koka, A. (2019). Effects of a web-based intervention for PE teachers on students' perceptions of teacher behaviors, psychological needs, and intrinsic 
This is a pre-print version of a paper currently under revision.

Please cite this paper as: Tilga, H., Kalajas-Tilga, H., Hein, V., Raudsepp, L.\& Koka, A. (2021). One-year Follow-up Data on the Face-to-face Autonomy-Supportive Intervention Program for Physical Education Teachers. Preprint.

motivation. Perceptual and Motor Skills, 126(3), 559-580.

3 Tilga, H., Kalajas-Tilga, H., Hein, V., Raudsepp, L., \& Koka, A. (2020). 15-month follow-up data on the Web-Based Autonomy-Supportive Intervention Program for PE teachers. Perceptual and Motor Skills, 127(1), 5-7. https://doi.org/10.1177/0031512519870914 one-day autonomy-supportive intervention on improving basic psychological needs, motivation, and behaviours of physical activity among middle-school students: A multidimensional approach. International Journal of Sport Psychology. 